\title{
More data for the money: Improvements in design and cost efficiency of electronic monitoring in the Danish cod catch quota management trial
}

Plet-Hansen, Kristian Schreiber; Bergsson, Heiðrikur; Ulrich, Clara

Published in:

Fisheries Research

Link to article, DOI:

10.1016/j.fishres.2019.03.009

Publication date:

2019

Document Version

Publisher's PDF, also known as Version of record

Link back to DTU Orbit

Citation (APA):

Plet-Hansen, K. S., Bergsson, H., \& Ulrich, C. (2019). More data for the money: Improvements in design and cost efficiency of electronic monitoring in the Danish cod catch quota management trial. Fisheries Research, 215, 114-122. https://doi.org/10.1016/j.fishres.2019.03.009

\section{General rights}

Copyright and moral rights for the publications made accessible in the public portal are retained by the authors and/or other copyright owners and it is a condition of accessing publications that users recognise and abide by the legal requirements associated with these rights.

- Users may download and print one copy of any publication from the public portal for the purpose of private study or research.

- You may not further distribute the material or use it for any profit-making activity or commercial gain

- You may freely distribute the URL identifying the publication in the public portal 


\title{
More data for the money: Improvements in design and cost efficiency of electronic monitoring in the Danish cod catch quota management trial
}

\author{
Kristian S. Plet-Hansen ${ }^{\mathrm{a}, *}$, Heiðrikur Bergsson ${ }^{\mathrm{b}}$, Clara Ulrich ${ }^{\mathrm{a}}$ \\ ${ }^{\text {a }}$ Technical University of Denmark, National Institute of Aquatic Resources (DTU Aqua), Kemitorvet, DK-2800 Kgs, Lyngby, Denmark \\ ${ }^{\mathrm{b}}$ Marine Biological Section, Department of Biology, University of Copenhagen, Strandpromenaden 5, DK-3000, Helsingør, Denmark
}

\section{A R T I C L E I N F O}

Handled by Bent Herrmann

Keywords:

Catch quota management

Discard

Electronic monitoring

Fully documented fisheries

Landing obligation

\begin{abstract}
A B S T R A C T
Electronic Monitoring (EM) with video is a tool often mentioned to ensure compliance with fishing regulations while vessels are at sea. Since 2008, several trials have been conducted in the European Union on the use of EM. One of the largest and longest running European trials was the 2010-2016 Cod Catch Quota Management trial (CCQM) in Denmark. This paper reviews the methods and experiences gained from this trial, with focus on the last two years where criteria for video audits were expanded and major technical developments took place. The cost-effectiveness and potential of EM for compliance, management and scientific purposes is discussed. The present study demonstrates that EM is capable of high precision detection of non-compliance with a discard ban and that developments in the transmission of EM data allowed for a smoother and more reliable Monitoring, Control and Surveillance (MCS) system. Although further developments are needed, especially within the field of automated image analysis, we conclude that EM is one of the few feasible tools where fisheries information and compliance can be ensured under a Landing Obligation.
\end{abstract}

\section{Introduction}

The use of Electronic Monitoring (EM) with video has been tested in a number of fisheries worldwide for more than a decade (van Helmond et al., in review). In certain Canadian fisheries, vessels are required to either carry EM with video or have on-board observers (Stanley et al., 2011) and New Zealand is currently set to introduce mandatory video installation as part of the country's fisheries management (Hersoug, 2018; Reddy, 2017). Several European countries conducted trials with EM from 2008 and onward (van Helmond et al., in review). The introduction of a discard ban in the European Union (EU), known as the Landing Obligation (LO) has increased the relevance of EM in an EU context. According to article 15 of the 2013 Common Fisheries Policy (CFP) of the EU, Member States are obliged to "ensure detailed and accurate documentation of all fishing trips". Observers and EM are stated as specific means for this while the article allows for other, nonspecified measures as long as Member States respect the principle of efficiency and proportionality (EU, 2013). Danish experiences with EM began in 2008 with a one year pilot project run by the National Institute of Aquatic Resources at the Technical University of Denmark (DTU Aqua) with the objectives of testing the use of EM on board trawlers, gillnetters and Danish seiners (Dalskov and Kindt-Larsen, 2009). The trial focused on estimating cod (Gadus morhua) discards from video and investigating whether fishers would be able to record them correctly. Following the promising results of this trial, a second trial known as the Cod Catch Quota Management trial (CCQM) began in April 2010. The CCQM focused on the control and management potential of EM and was run as a collaboration between the Danish Fisheries Agency and DTU Aqua (Ulrich et al., 2015). After 2014, the CCQM underwent several changes. In 2015 and 2016 the trial was run solely by the Danish Fisheries Agency and its purpose shifted to focus more on developments for species recognition, camera quality and length measurements (Bergsson et al., 2017; Bergsson and Plet-Hansen, 2016). The last CCQM data collection in 2016 concluded almost seven years of catch quota management verified by EM in Denmark. In the present article, we present the technical developments and lessons learned from the CCQM. A few studies have already been published on this trial, including studies on the behavioral effect of EM with video on Danish vessels (Kindt-Larsen et al., 2011; Ulrich et al., 2013), a first analysis on the trial outcomes over the period 2010-2014 (Ulrich et al., 2015), and a study on fishers' and fisheries inspectors' views (Plet-Hansen et al., 2017). The present study focuses thus on the most recent developments and experiences of the CCQM trial in 2015 and 2016. The objectives are to analyze the discards patterns but also to describe the evolution of technology and data handling processes, and document the best practice experiences gained that improved the reliability and efficiency of

\footnotetext{
* Corresponding author.

E-mail address: kspl@aqua.dtu.dk (K.S. Plet-Hansen).
} 
the EM system and reduced the costs. This knowledge is useful information for future EM programs, as technical specifications are usually only little described in EM published literature, being often hidden in unpublished reports.

\section{Material and methods}

\subsection{Area and participants}

In 2010 and 2011, the Danish CCQM trial covered fisheries conducted in the North Sea, Skagerrak and the Baltic Sea (Dalskov et al., 2012, 2011). After 2011, the trial was geographically limited to monitor vessel operations in the North Sea and Skagerrak (Bergsson et al., 2017; Bergsson and Plet-Hansen, 2016; Plet-Hansen et al., 2015). Incentives for participation were exemption from days-at-sea regulations and a cod quota uplift of $30 \%$ for the first 100 tonnes of cod TAC and a $20 \%$ increase of any cod TAC above 100 tonnes held by the vessel at the beginning of the year. The Danish fishery for demersal species like cod has been governed by a Vessel Quota Share (VQS) system since 2007 (Andersen et al., 2010). It was therefore specified that any additional acquiring of cod quota throughout the year via the VQS-system would not be subject to the quota uplift for trial participation. The reasoning behind the days-at-sea exemption and quota uplift were that the Catch Quota was targeted at cod and the uplift was set to reflect the overall discard estimate for the Danish fishing fleet (Dalskov et al., 2012, 2011; Ulrich et al., 2015). Participating skippers were required to fill in their electronic logbook (eLog) on a haul-by-haul basis, including position, date and time for setting and hauling of gear, the landings and the discards. The number of participating vessels in the trial varied from 7 in 2010 up to 24 participants in 2012. In 2015 and 2016, 13 and 12 vessels participated in the trial, respectively. A full list of participating vessels is available in the supplementary Table A1.

\subsection{EM technology and data flow}

Until 2014, the EM system provided by Archipelago Marine Research Ltd. was used. The system consisted of a GPS, hydraulic pressure and drum rotation sensors as well as video cameras. Recorded data was stored on a control box hard drive. Data transmission was done manually by fisheries inspectors who replaced the vessels' hard drives while in port and sent the collected hard drives by postal order to the Danish Fisheries Agency's head office (Ulrich et al., 2015). From September 2014, the vessels' EM systems were replaced with the Anchor Lab K/S Black Box Video system (Anchor Lab K/S, 2017). Replacements were carried out when planned fishing trips or maintenance tasks kept the participating vessels in port for longer durations (more than one week). The new system acquired vessel positions using a GPS antenna on the wheelhouse where antennas for data transmission via GSM, $3 \mathrm{G}, 4 \mathrm{G}$, Wi-Fi or satellite were placed as well. Drum rotation sensors mounted on winches provided data on setting and hauling of gear. In 2015, all video footage was recorded using 2 megapixel (MP) wide-angle lens cameras. In 2016, all cameras recording the vessels discard chute were replaced by 3 M P and 5 M P square-lens cameras to get better imagery for length measurements of individual fish. The standard number of cameras was four but the EM system handled six cameras on some vessels in both 2015 and 2016. Recorded data from cameras, GPS and rotation sensors was stored on two on-board 1 TB hard drives. Data transmission via GSM, 3 G, 4 G or Wi-Fi to the Danish Fisheries Agency took place while vessels were in port vicinity. A two month trial transmitting sensor data twice a day while at sea via satellite connection was tested as a proof of concept and proved to be successful. In practice however, data transmission was done online while vessels were in port. During 2015 and the first half of 2016, the internet provider allowed for transfer rates fluctuating between 5 megabit per second (Mbit/s) and $90 \mathrm{Mbit} / \mathrm{s}$. The transfer rates mainly varied between 10-20 Mbit/s depending on location of vessel within the port. In the second half of 2016, data load transmission was improved by changing the compression standard for video records from H.264 to H.265 for some cameras whereby video data could be compressed by at least $15 \%$ without loss of image quality. Additionally, the internet provider in the main harbor for participating vessels (Hanstholm) was also changed. The new internet provider made it possible to achieve standard transfer rates of 50-90 Mbits/s.

\subsection{Video audit software, hardware and procedures}

During 2010 to 2014, audited videos would receive a comment if something out of the ordinary was seen. This included comments on possible errors or malfunctions, such as system breakdowns, unclean camera lenses etc. If no comment was made, the video was of sufficient quality. From July 2015, a grade system of video quality was introduced, where low grades had to be accompanied by a comment from the video auditor on the reason(s) for the given grade. Until 2015, video auditors divided discards into two categories for registration: Cod and Other. In practice, this meant that only cod discards were well documented, because the term "Other" could cover a large variety of species and only provided an estimate of the total discard of fish from the given vessel. Discard estimates were entered into a spreadsheet as mass per haul in kilograms. Before July 2014, mass estimation was based on the empirical knowledge that video auditors gained. That is, auditors would estimate the length of a discarded fish based on their knowledge of the field of view in the video and of visible fixed structures for the specific vessel. They would then estimate the mass of the discarded fish based on their assessment of its length and condition. If in doubt, auditors could refer to a mass-length relationship table. All lengths were based on the auditors own estimate, since no software measuring tools were available. From July 2014 this was changed by 1) the introduction of a grid overlay and 2) alteration of audit procedures and recorded species.

\subsection{Introduction of a grid overlay}

During 2014, re-measurements of conveyor belts and adjacent structures on the vessels were conducted. This knowledge of the dimensions of several objects within the field of view made it possible to develop and calibrate a grid overlay system. The first version of the grid overlay was launched for video audit in July 2014 and was a standalone program that would display a transparent grid which could be placed on top of the video footage from the EMI software (Fig. 1). After the change in EM provider and an initial transition period, the grid program was incorporated as part of the Black Box Analyzer and improved by adding a measuring tool to the analysis software (Fig. 1).

\subsection{Alteration of audit procedures and recorded species}

In conjunction with the implementation of the grid overlay, the video audit procedures were adapted continuously leading to four different audit methods applied over the full CCQM duration (Table 1). Method 1 with manual entry of discard mass estimates into a spreadsheet was replaced with a custom interface with an integrated database (Method 2). The database was connected to a custom made acquisitioning software where the video auditors could directly enter length estimates at $5 \mathrm{~cm}$ length intervals. Length estimates would automatically be converted to mass for each recorded fish based on the length-mass relationship for the species, and the estimated discard mass would be relayed back to the database together with haul info. The discard category "Other" was discontinued because the data was somewhat unusable and focus was moved to discards of cod, saithe (Pollachius virens), whiting (Merlangius merlangus) and haddock (Melanogrammus aeglefinus). In October 2015, hake (Merluccius merluccius) was included in the audit too (Method 3). All other discards were no longer registered. This meant a change in the type of recorded data, from focusing on a high data quality for discards of one species and low 


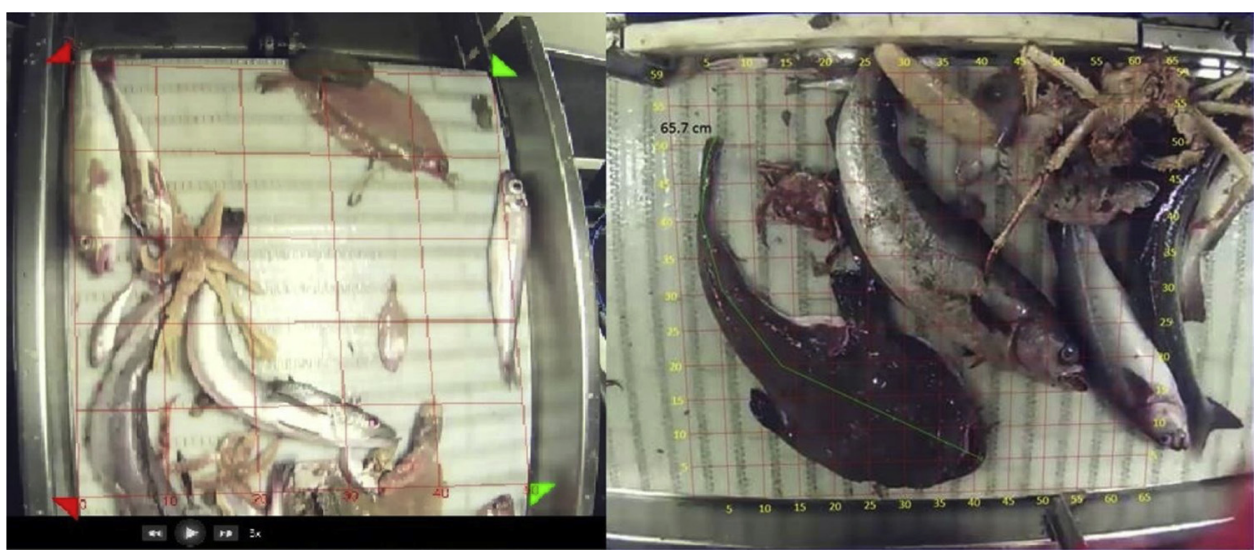

Fig. 1. Left: Example of image for video audit with the first version of the grid overlay. Grid scale set on this example was a $10 \mathrm{~cm}$ interval. Right: Example of image for video audit with the final grid overlay and measuring line integrated in the Black Box Analyzer. The image shows the measuring line on a monkfish (Lophius spp.) of $65.7 \mathrm{~cm}$ in length in a curved position. The scale set for this grid overlay was $5 \mathrm{~cm}$ interval.

data quality but total discard mass for all other commercial species, to high data quality for discards of 4 (later 5 ) species and no data for all other discards. These changes also led to a change in the computer hardware used for discard recordings, detailed elsewhere (Bergsson et al., 2017; Bergsson and Plet-Hansen, 2016). From July 2016, Method 4 was introduced, where a Shuttle Pro V2 Contour Design was used to navigate in the video footage (e.g. fast forward or replaying footage) together with a Logitech ${ }^{\circledR}$ G502 mouse. EM data would be transmitted to the Danish Fisheries Agency's webservice. The project manager would ensure merger of hauls in the EM system and reported in the eLog for verification of compliance. Random hauls would be selected for audit, whereby these would appear for video auditors in the custom interface. Auditors would not be able to view eLog data for a haul until the haul audit had been completed. Audit for selected hauls would cover all discards of cod, hake, haddock, saithe and whiting registered and the length of each discarded fish was estimated by placing the measuring line in the Black Box Analyzer manually. The measuring line could be bent when fish were lying in a curved position (Fig. 1). The length estimate would be recorded directly in the data acquisitioning software at a $0.1 \mathrm{~cm}$ scale and used for the length-mass relationship. Additionally, a snip of the video sequence containing the discarded fish was taken and saved automatically when measuring the fish. Thus, with Method 4 every single discard of cod, whiting, saithe, hake and haddock would be recorded with an ID-marker, video stamp, length measurement, mass estimate and a picture of the fish. This was done to enhance the integrity of the audit as it made future verification of species and size estimates easy. For further overview of the gameboard, gamer mouse and Shuttle Pro used for video audit we refer to Bergsson et al., 2017. It is important to remember that all improvements in discard assessment were based on the length measurements and that the mass of the discards would be derived from the length-mass relationship of each species. Variation in fish mass due to condition was not included such that data from the CCQM is more robust with respect to length and number records than with respect to mass records.

\subsection{Personnel}

It was recognized that viewing video footage of catch processing's as a full time job would likely lower the quality of the audits as this can become a tedious task. Therefore, student workers were hired as video auditors on part-time contracts of $15 \mathrm{~h}$ per week. The first month of employment would serve as a training period where a senior video auditor would look through videos with the newly hired video auditor. To verify the validity of audits, $10 \%$ of all audited video sequences would be re-audited by another video auditor to double-check the discards. If discrepancies occurred the video auditors would go through the specific video sequence together to investigate when and why the assessment differed. Four students served as auditors in 2015 and 2016.

\section{Results}

\subsection{Malfunctions and countermeasures}

Table 2 presents a list of reported errors during the years 2010-2016 and what was done to counter these. The total number of audited hauls was 7,690 , meaning that for the whole period $2010-2016,11.4 \%$ of video sequences selected for audit turned out to have an error, ranging from the video sequence being non-existent so that no audit could be done, to light reflections or smudge on the camera lenses being a nuisance for the video auditor.

\subsection{Time used per audited haul}

Technical developments served the purpose of enhancing the quality of the recorded data and reducing the time needed for auditing a haul. As the majority of participating vessels had conveyor belts and these tended to include the hauls with the largest volumes of discards, the developments mainly focused on optimization for vessels with conveyor belts. Method 4 lowered the average time needed for video audit of hauls from vessels with conveyer belt compared to the average

Table 1

Summary of audit methods applied in the CCQM. Species identification was based on human interpretation for all methods.

\begin{tabular}{|c|c|c|c|}
\hline Audit method & Recording specifics & Audit grouping and coverage & Duration \\
\hline Method 1 & $\begin{array}{l}\text { Spreadsheet recording. Human estimate of mass based on length and condition. Data } \\
\text { recorded as } \mathrm{kg} \text { for all audited groups. }\end{array}$ & $\begin{array}{l}\text { All discards recorded. Grouped as Other or as } \\
\text { Cod. }\end{array}$ & $\begin{array}{l}\text { April } 2010 \text { - January } \\
2015\end{array}$ \\
\hline Method 2 & $\begin{array}{l}\text { Custom interface and integrated database. } 5 \mathrm{~cm} \text { length interval record based on human } \\
\text { interpretation with grid overlay as support. Record of number of each discard per } \\
\text { length group. Automatic mass estimate based on mass-length equation. }\end{array}$ & $\begin{array}{l}\text { Discards of cod, haddock, whiting and saithe } \\
\text { recorded. All other discards ignored. }\end{array}$ & $\begin{array}{l}\text { January } 2015- \\
\text { October } 2015\end{array}$ \\
\hline Method 3 & Same as Method 2. & $\begin{array}{l}\text { Discards of cod, haddock, whiting, saithe and } \\
\text { hake recorded. All other discards ignored. }\end{array}$ & $\begin{array}{l}\text { October } 2015 \text { - July } \\
2016\end{array}$ \\
\hline Method 4 & $\begin{array}{l}\text { Custom interface and integrated database. } 0.1 \mathrm{~cm} \text { length estimate recorded based on } \\
\text { measuring line. Automatic length and number recorded based on human image } \\
\text { analysis. Automatic mass estimate based on mass-length equation. }\end{array}$ & $\begin{array}{l}\text { Discards of cod, haddock, whiting, saithe and } \\
\text { hake recorded. All other discards ignored. }\end{array}$ & $\begin{array}{l}\text { July } 2016 \text { - December } \\
2016\end{array}$ \\
\hline
\end{tabular}


Table 2

List of reported errors during the years 2010-2016 and what has been done to counter these.

\begin{tabular}{|c|c|c|c|}
\hline Type & Number & Share & Countermeasure \\
\hline $\begin{array}{l}\text { Discard hard or impossible to } \\
\text { identify }\end{array}$ & 286 & $32.6 \%$ & $\begin{array}{l}\text { Replacing cameras to get clearer view. } \\
\text { Adding cameras to get continuous view of fish. } \\
\text { Communicating with fishers on adaption of working routines (e.g. instruct fishers to stop tossing fish or ensure clear } \\
\text { view of baskets with discard) }\end{array}$ \\
\hline Dirty camera & 168 & $19.1 \%$ & $\begin{array}{l}\text { Applying NanoCover/Rain Repellent (Turtle Wax) to the lenses to reduce the risk of smudge sticking to the lenses. } \\
\text { Increase fishers' awareness on cleaning procedures by introducing a video quality grade system }\end{array}$ \\
\hline Blurry picture & 154 & $17.5 \%$ & Higher resolution and video quality of cameras \\
\hline Water droplet & 119 & $13.6 \%$ & Tilting cameras whereby water droplets aggregate in the corner or bottom of the camera view rather than in the center \\
\hline Video lost & 59 & $6.7 \%$ & $\begin{array}{l}\text { Transmit video data via the internet whereby manual replacement of hard drives ended. This removed the risk of } \\
\text { damage or loss of hard drives which had previously accounted for virtually all lost videos }\end{array}$ \\
\hline Fisher blocking camera view & 33 & $3.8 \%$ & Reposition cameras to avoid areas where daily work routines would block the view \\
\hline Video gap & 28 & $3.2 \%$ & Using a more robust EM system \\
\hline Camera breakdown & 25 & $2.8 \%$ & Using a more robust EM system/cameras \\
\hline Light reflection or lights are off & 6 & $0.7 \%$ & $\begin{array}{l}\text { Light reflection might be countered by repositioning cameras. } \\
\text { Periods with the lights turned off was not an issue after } 2014 \text { as the new camera system included infrared video } \\
\text { recording }\end{array}$ \\
\hline Total errors & 878 & $100.0 \%$ & \\
\hline
\end{tabular}

Table 3

Average and standard deviation for video audit times, haul duration and catch processing. Audit and haul times are presented for all years (2010-2016) as well as for the last six months of 2016 where Method 4 was employed. Data on catch processing duration is only available for Method 4. CB = Vessel with conveyer belt. $\mathrm{NCB}=$ Vessels without conveyer belt. *Catch processing times could not be made for gillnetters. These averages are therefore solely for trawlers or Danish seiners without conveyer belt.

\begin{tabular}{|c|c|c|c|}
\hline Parameter & $\begin{array}{l}\text { Vessel } \\
\text { group }\end{array}$ & $\begin{array}{l}\text { Average } \\
{[\mathrm{min}]}\end{array}$ & $\begin{array}{l}\text { Standard Deviation } \\
\text { [min] }\end{array}$ \\
\hline Audit time, All years & $\mathrm{CB}$ & 30.5 & 28.0 \\
\hline Audit time, All years & NCB & 29.2 & 25.2 \\
\hline Haul time, All years & $\mathrm{CB}$ & 322.9 & 108.4 \\
\hline Haul time, All years & NCB & 236.8 & 155.8 \\
\hline $\begin{array}{l}\text { Catch processing time, } \\
\text { Method } 4\end{array}$ & $\mathrm{CB}$ & 75.8 & 41.5 \\
\hline $\begin{array}{l}\text { Catch processing time, } \\
\text { Method } 4\end{array}$ & NCB & $90.3^{*}$ & $91.9^{*}$ \\
\hline Audit time, Method 4 & $\mathrm{CB}$ & 21.4 & 15.3 \\
\hline Audit time, Method 4 & NCB & 35.0 & 42.7 \\
\hline Haul time, Method 4 & $\mathrm{CB}$ & 281.8 & 103.1 \\
\hline Haul time, Method 4 & NCB & 266.4 & 255.7 \\
\hline
\end{tabular}

audit time for the full duration of the CCQM (Table 3). For Method 1 (Trial start to January 2015), the average time ratio (audit time/haul duration) was $0.151( \pm 0.164)$ for vessels with conveyer belt and 0.158 ( \pm 0.149 ) for vessels without conveyer belt, meaning that the audit time was roughly $15 \%$ of the haul duration on average for the first audit method. This fell with Method 2 (January 2015 to July 2016) to $0.047( \pm 0.035)$ for vessels with conveyer belt and $0.094( \pm 0.072)$ for vessels without conveyer belt. Changes in average times were negligible between Method 2 and Method 3 but Method 4 with more precise length estimates (July 2016 to trial end) led to a rise in the average time ratio to 0.093 ( \pm 0.091) for vessels with conveyer belt and 0.122 ( \pm 0.077) for vessels without conveyer belt (Fig. 2).

\subsection{Digital data transmission}

During 2015 and 2016 the transfer rate fluctuated between 5 megabit per second (Mbits/s) and $90 \mathrm{Mbits} / \mathrm{s}$, with the majority of rates at 10-20 Mbits/s. Depending on the length of the fishing trip and the length and quality of video footage, the accumulation of data would differ. Whether a full data transmission was possible depended on the size of the data accumulated, transfer rate and port time. Participating Danish seiners and gillnetters had sufficient port time to transfer the recorded data on all occasions in 2015 and 2016. However, with an average data accumulation of $71.4 \pm 15.5$ GB per trip, demersal trawlers would on average need approximately $8 \mathrm{~h}$ of port time for a full data transmission given a $20 \mathrm{Mbit} / \mathrm{s}$ transfer rate. As transfer rates of 20 Mbit/s were not achieved at all times and due to port times as short as $4 \mathrm{~h}$, the participating demersal trawlers accumulated data on the onboard data storage. When a vessel entered port the oldest data would be transmitted first. If a full data transmission could not be achieved, the recorded data from the next fishing trip would be added to the previous. This lead to a spiraling effect because more and more data had to be transmitted the next time the vessel was in port. This meant that the time lag between video recording and video audit was larger for some trawlers than for Danish seiners and gillnetters. On one occasion in 2015 , it became necessary to manually exchange a hard drive on a demersal trawler in order to catch up with the accumulated data load. In all other instances, the storage capacity of $1 \mathrm{~TB}$ on hard drives and occasional longer port times made it possible to ensure full online data transmission. The increase in transfer rates in the last half of 2016 reduced the risk of data accumulation as the standard transfer rate of 50-90 Mbit/s more than halved the time needed for full data transmission.

\subsection{Frequency distribution}

Methods 2-4 made it possible to plot the number of discards pr. species pr. length interval in a frequency plot (Fig. 3). Of the five audited species, hake had the highest number of discarded individuals (1363 individuals on average per month, equal to 20,440 individuals recorded during 2015-2016), followed by saithe (1070 individuals on average per month), haddock (343 individuals per month), whiting (332 individuals per month) and cod (128 individuals per month). In terms of discards above the MCRS, hake in the North Sea had the highest percentage ( $99.35 \%$ of discards > MCRS) followed by saithe in Skagerrak (90.13\%), whiting in Skagerrak (83.54\%), hake in Skagerrak (78.32\%), haddock in Skagerrak (78.21\%), cod in Skagerrak (70.56\%), whiting in the North Sea (69.24\%), saithe in the North Sea $(56.64 \%)$, cod in the North Sea (45.95\%) and haddock in the North Sea (37.76\%). A logistic regression model was used to test whether discard frequency below or above the MCRS depended on the management area (Skagerrak and North Sea). No statistically significant dependency of management area was found for any of the audited species. Non-compliance with the LO has been detected as haddock discards have been identified in both years despite haddock being subject to the LO in 2016 (EU, 2015).

\subsection{Estimation of costs}

In 2016, there were 396 Danish fishing vessels above $12 \mathrm{~m}$ in length 

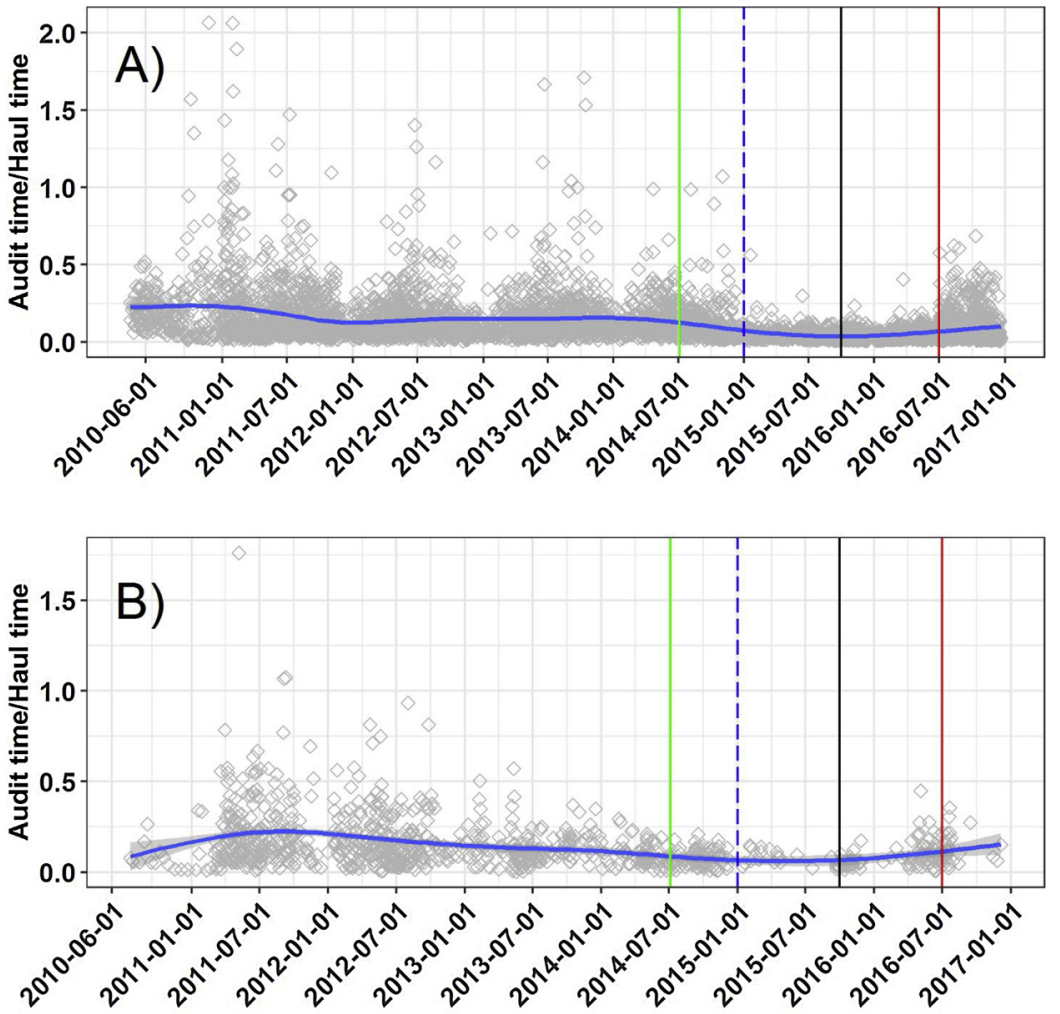

Fig. 2. Video audit duration/ haul duration divided by vessels with and without conveyor belt from 2010-2017. A): Vessels with conveyor belt. B): Vessels without conveyor belt. Green vertical line represents the first replacement of EM hardware and first use of the grid overlay and the database with interface software for audit, blue vertical dashed line represents the end of the audit of discard category "Other" and beginning of length interval audit for cod, saithe, haddock and whiting (Method 2), black line represents the inclusion of hake for length interval video audit, bringing the audited species to five (Method 3), red vertical line represents the onset of the final length measurement method using a line overlay for all recorded discards of the five audited species (Method 4) (For interpretation of the references to colour in this figure legend, the reader is referred to the web version of this article).
(STECF, 2017). Assuming that the 12 vessels in the CCQM are representative in terms of hauls and installation costs, a rough total estimation for an EM based control of all Danish vessels above $12 \mathrm{~m}$ in length can be calculated using the budget for the 2016 run of the CCQM (Table 4). For the estimate, the data gathered in 2015 and 2016 has been extrapolated to the rest of the Danish large scale fleet, amounting to roughly 1200 TB of data recorded each year. Based on these estimates, the total cost of having EM with video on all Danish fishing vessels above $12 \mathrm{~m}$ in length is roughly 1.7 million $€$ annually recurring costs (2nd year total cost), with an additional 3.3 million $€$ needed for initial investments in equipment, installation and training (1st year total cost of 4.9 million $€$ ). This corresponds to an average of $4200 €$ per vessel per year in recurring costs and $8300 €$ per vessel in initial costs. Besides the uncertainty in adjusting for all possible costs associated with an EM scheme it should also be noted that the estimate was adjusted to the fact that the audit coverage was above the minimum $10 \%$ requirement in 2016 (Bergsson et al., 2017). However there will be uncertainty as to whether this and other specifics for the 2016 run of the CCQM can be factored in directly. Likewise, data storage costs can vary significantly depending on the criteria for backup, data redundancy, data retrieval time and whether cloud options are permitted or only in-house storage is allowed.

\section{Discussion}

\subsection{Main developments}

Key improvements in the CCQM were; (i) transmission of EM data via the internet, which led to the possibility of adjusting the camera placements while watching the video footage in real time at the head office and reduced certain logistics involved in the project. (ii) the move from a spreadsheet recording system which relied heavily on human interpretation and manual entry, to a system with limited manual edits by video auditors and where the human interpretation was focused at species recognition and location of specific measuring points. The developments in the CCQM has allowed for better data on some aspects of the fisheries that are traditionally difficult to address. The recording of all discarded fish by length and estimated mass of several species makes it possible to analyze the discard size composition. Enhancement of audit precision and data acquisition came at the cost of increased audit duration relative to the haul duration. A clear understanding of the management aims motivating the introduction of an EM system is thus a key factor for designing the best trade-offs between costs and accuracy.

\subsection{Reliability}

Some of the lessons learned seem retrospectively as common sense (e.g. do not install cameras where their view will be blocked during catch processing's working procedures). Nevertheless, when comparing the overall decline in the number of video sequences with malfunctions to the countermeasures done in the CCQM it seems evident that simple engineering solutions may be enough to improve the reliability of the EM system. We therefore included even the simple errors and countermeasures in this article to pass on the know-how gained from the trial. Ensuring clean cameras with unobstructed view of catch processing was a continuous issue during all the years of the CCQM. Drawing fishers' attention to the issue often helped for a while but frequent follow-ups were needed. Several participants stated that they would forget that the cameras were present. Although this was a nuisance in terms of keeping camera lenses clean, the positive interpretation of such a statement is that fishers' working procedures were not hindered or altered due to the presence of cameras. Participating fishers in the CCQM have previously stated that they forget the presence of the cameras (Plet-Hansen et al., 2017). Of the more technical developments employed to counter malfunctions, the possibility to transmit EM data via the internet was the greatest improvement. This measure countered an important cause of malfunctioning, i.e. lost or damaged hard drives during transport whereby relatively large quantities of video footage previously had been lost. The transmission also made it possible for video auditors to see the actual camera view while it was being installed, making it possible to make adjustments over the phone and 

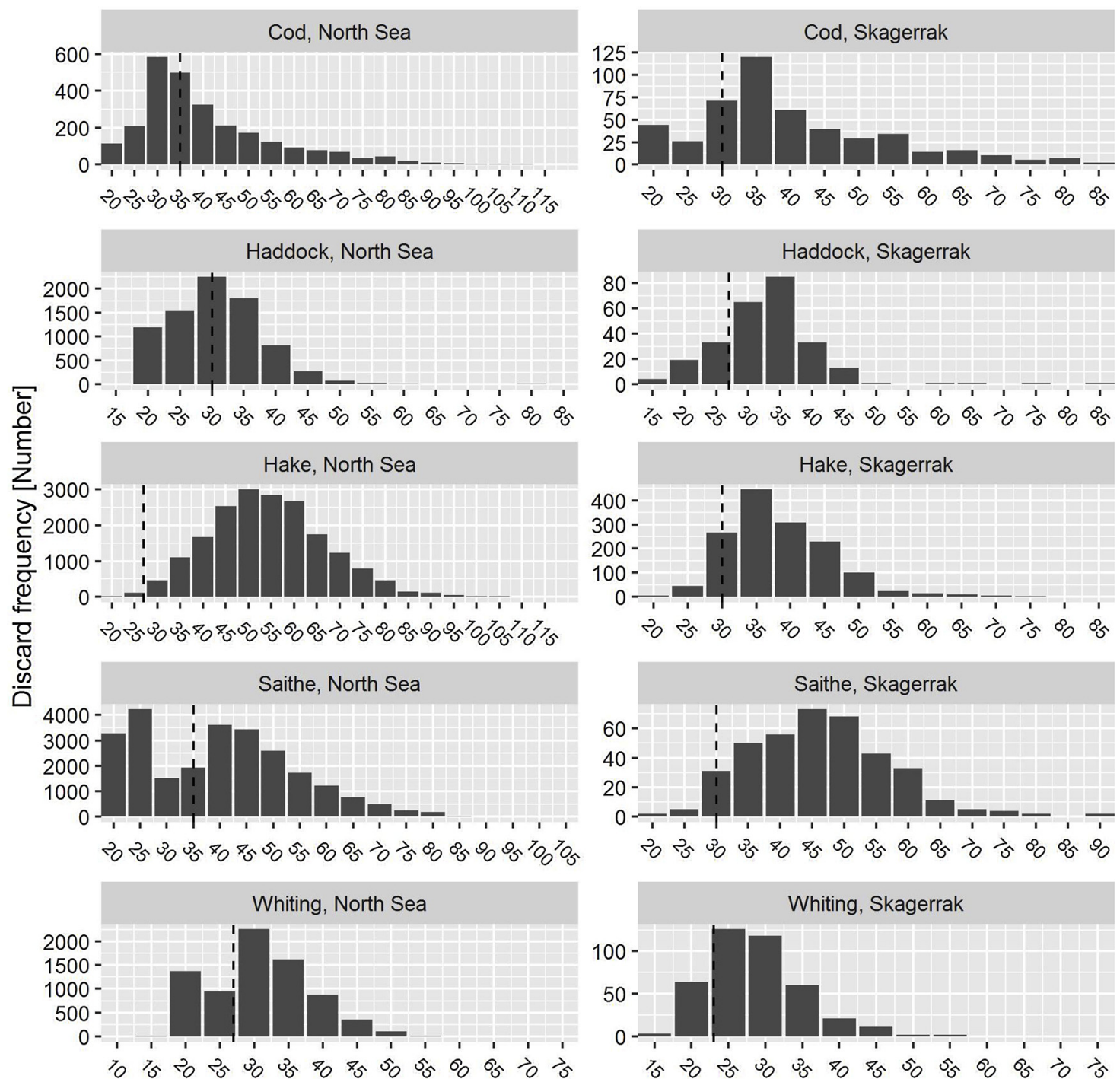

Length $[\mathrm{cm}]$

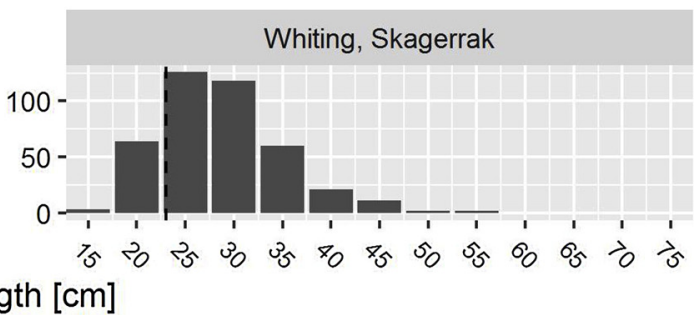

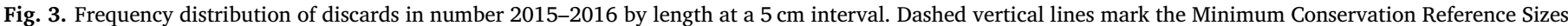

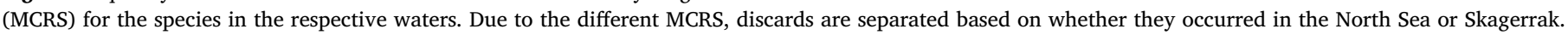
Note that hake was not audited until October 2015.

Table 4

Assumed expenses for EM monitoring. Values are based on the Danish Fisheries Agency's expenses during 2016, except for data storage expenses. *Average for several staff groups. ${ }^{* *}$ Data storage cost is based on a cloud storage solution for 1200 TB of data collected annually.

\begin{tabular}{llll}
\hline Expense type & $\begin{array}{l}\text { Cost }(€), \text { one } \\
\text { unit }\end{array}$ & Recurring & $\begin{array}{l}\text { Cost }(€), 396 \\
\text { vessels }\end{array}$ \\
\hline EM equipment & 4,139 & Once & $1,638,926$ \\
EM installation & 4,027 & Once & $1,594,631$ \\
Video audit computer & 1,074 & Once & 20,523 \\
Training & 902 & Once & 17,239 \\
Salary, video audit & 36,156 & Annual & 691,007 \\
Salary, support and & 48,190 & Annual & 515,410 \\
$\quad$ & & \\
$\quad$ management* & 2,953 & Annual & 56,438 \\
Additional software licenses & 5,754 & Annual & 40,687 \\
EM maintenance & 1,119 & Annual & 158,198 \\
Internet connection, rent and & 392 & Annual & 155,034 \\
$\quad$ maintenance & & & \\
Data storage** & 46,025 & Annual & 46,025 \\
Total cost, 1st year & & & 4.9 million $€$ \\
Total cost, 2nd year & & & 1.7 million $€$ \\
\hline
\end{tabular}

thereby optimize the placement of cameras. Finally, online transmission reduced the logistics involved in data transmission considerably. While data transmission via the internet could become challenged by large data quantities and short port durations, the increase in transmission rates and reliability as already experienced in 2016 should reduce this risk. The current trend of faster and more reliable internet connection only enhances the benefit of using digital data transmission.

\subsection{Cost of EM with video}

Depending on the setup for video auditors and the minimum audit coverage, the costs of video analysis can vary considerably. The estimate of the costs of fitting all Danish vessels above $12 \mathrm{~m}$ in length with EM should be seen as exactly this: an estimate. Due to inherent differences between vessels in terms of fishing operations, target species, vessel specifics, fishing areas and possibly crew mindset, it is a rough assumption to simply extrapolate the costs of the CCQM onto all Danish vessels above $12 \mathrm{~m}$ in length, including pelagic trawlers. Firstly, other vessels in the Danish fishing fleet will have different target species and areas, e.g. pelagic trawlers where the species composition is likely to be more homogenous than for demersal trawlers, whereby the audit time 
is likely to be shorter. Secondly, the vessels participating in the CCQM might have been those who would benefit from the trial setup or have adapted their fishing strategies to the trial, something that has been reported for a Dutch trial on EM and the CCQM has been criticized for (Msomphora and Aanesen, 2015; van Helmond et al., 2016). Thirdly, the minimum accepted audit coverage may be easy or hard to obtain depending on the needed viewer time for the vessel in question. This can vary due to multiple factors like catch composition and volume, working procedures and quality of video footage due to available setup for cameras on the vessel or how well the lenses are kept clean and whether the view is unobstructed. Fourth, the security and storage costs associated with the collected video material can vary a lot depending on how, where and for how long the video material is to be kept. One option is for vessels to store their own data for a specified period (e.g. 5 years) and making it mandatory for vessel owners to hand over video material to authorities upon request, following the principle of trucks' or airplanes' black boxes. Another option is for the fisheries authorities to collect and store all video material on their own servers and yet another option is to contract private companies for storage of video data. Depending on the approach, the associated cost can vary significantly. In addition, technical specifics such as redundancy, the split between archive data and immediate data and data storage retrieval time will also influence the cost of data storage. Lastly, the needed audit time and thereby associated costs will vary depending on the EM setup, vessels covered by EM, fishing areas and the number of species accounted for in the audit. The changes in audit procedures in the CCQM had a direct effect on the average audit time over haul duration where the swiftest audit method was the one with a $5 \mathrm{~cm}$ length interval record of species. The inclusion of hake is not possible to discern in the audit time but the change to a more precise length measurement increased the needed audit time. Another example is that Mortensen et al. (2017) reported an average of $41 \mathrm{~min}$ per haul used for video audit, whereas the CCQM had an average audit time of $21 \mathrm{~min}$ per haul for vessels with conveyor belt and $38 \mathrm{~min}$ for vessels without conveyor belt in the last year of the trial. The two trials had similar vessel composition and the EM system applied was the same but the trial conducted by Mortensen et al. (2017) also audited discards of plaice (Pleuronectes platessa) and Nephrops (Nephrops norvegicus) in addition to cod, saithe, hake, haddock and whiting. Additionally, Mortensen et al. (2017) covered vessels operating in the Baltic Sea and the audit procedures were different by not incorporating the gameboard setup used in the CCQM at the same time (2015). Besides the effect on needed audit time based on species coverage and analysis setup, the catch volume, catch composition and corresponding catch processing times have an effect on the needed audit time. Based on vessel and time of the year, fishing areas, target species, catch volumes and catch composition can change, meaning that the catch processing times for hauls and corresponding audit times can vary between vessels and on a temporal scale as well. The LO should make it easier and more uniform to audit catch processing because discarding shall not take place - at least not for species regulated by a quota or a MCRS. However, because discards will have to be documented if they occur and because exemptions from the LO exist, the LO may not actually reduce the needed audit time (EU, 2013; Needle et al., 2015). It is therefore difficult to estimate the final costs of applying EM as a large part of the fisheries management. The estimate does give an overall idea of the funding needed if EM with video should serve as a control measure and thereby gives a basis for comparison with other measures to ensure compliance with the LO.

\subsection{Alternative compliance measures}

A range of management tools other than EM for at-sea discard detection and estimation exist. These include aerial patrols, patrol vessels, drones, self-sampling and onboard observers. Norway is an example where a discard ban has been in place for decades and where extensive at-sea control by patrol vessels is used for enforcement (Gullestad et al.,
2015). The Norwegian at-sea fisheries control is in the order of 2000 inspections per year and for this it is estimated that Norwegian Coast Guard spent approximately 70 million $€$ in 2011 (Gullestad et al., 2015; James et al., 2019). Likewise, it is estimated that the cost of fitting all UK vessels above $10 \mathrm{~m}$ in length will amount to around 5.8 million $€$ compared to the current cost of the UK fisheries control at roughly 23.3 million $€$ (European Union Committee, 2019). In addition, aerial patrols, patrol vessels and drones are used for inspection, meaning that these capture only a snapshot of the fishing activities. Self-sampling allow for continuous coverage at a low cost, but the quality of the data may be questionable and therefore need verification (James et al., 2019). Onboard observers is currently the only MCS tool which can attain the same coverage level as EM and in fact for some metrics, such as age and mass estimates, allow for higher quality data than EM (Gilman et al., 2019; James et al., 2019). However, as other papers concerning EM with video have previously stated, the running costs of fisheries control with EM is lower than a similar coverage obtained with on-board observers and issues like observer safety at-sea and space limitations for an extra person on a vessel must also be taken into account (Gilman et al., 2019; James et al., 2019; Kindt-Larsen et al., 2011; Mangi et al., 2015; Mortensen et al., 2017; Needle et al., 2015).

\subsection{EM with video as a management tool}

The possibility to record all audited discards by length address a current challenge for the EU fisheries management as lack of data for this has been pointed to as a challenge for the promotion and management of the LO because different incentives are required based on whether catches are seen as unwanted because of size or quota constraints (Catchpole et al., 2017). The percentage of discards above MCRS is generally higher in Skagerrak than the North Sea but based on a test using a logistic regression model, this is not a significant effect. Except for cod and haddock in the North Sea, more than half of discards in numbers were above the MCRS for the audited species. Especially hake in the North Sea and saithe in Skagerrak deserve attention as more than $90 \%$ of the fish discarded were above the MCRS. The large majority of hake discards are above the MCRS. This could be driven by large shares of damaged fish or catch volumes exceeding the vessel quota as hake was not covered by the LO during the CCQM, meaning that over quota catches had to be discarded and hake has been identified as a species for which the EU quota allocations between Member States may be problematic due to shifts in species distribution (Baudron and Fernandes, 2015). However, as prices for hake are generally lower in Denmark than for instance for cod or haddock, it is possible that discards of hake may also be driven by a wish to keep storage capacity open for potential future catches of higher value species. As the CCQM was directed at monitoring cod catches, the inclusion of hake in the video audit was solely done for the purpose of gaining experience in species recognition. Therefore, analysis of potential discard drivers has not been performed in this study. Catchpole et al. (2018) identify damaged fish as the reason for the unwanted status in $92 \%$ of hake catches, "No market" accounting for additional $6 \%$, leaving undersized fish as the reason for the remaining $2 \%$ of unwanted hake catches. The discards of whiting and saithe are roughly fifty-fifty above and below MCRS, whereas the majority of discards of haddock and cod are at or below the MCRS in the North Sea. This suggests, that for these two species, discarding could be driven mainly by size. However, it is important to note that cod was the species for which the CCQM was directed, meaning that participants had to acquire additional quota if they caught more cod than their initial quota. From a managers' point of view, EM with video is impossible to ignore for MCS purposes in fisheries managed with either Catch Quotas or discard bans. Verifying such management measures require on-board presence either full-time or at random. At-sea control can check for a certain level of compliance but to actually enforce a discard ban, on-board observers or EM with video seem currently the most trustworthy options (Hedley et al., 2015; 
Plet-Hansen et al., 2017). Rather than opposing one against the other, using these two MCS tools in conjunction may be desirable to ensure the full validity of the fisheries management as both tools have advantages and disadvantages (Catchpole et al., 2017; Gilman et al., 2019). Onboard observers allow for the greatest sample detail, but for compliance purposes, full coverage is needed. EM with video may lack sample details but allow for full coverage without the need of full review of video footage for compliance purposes. Video sequences selected for audit can be sampled randomly and used for verification of compliance with selfreporting regulations. In a European context, EM with video could thus verify whether requirements on discard entries in the eLog are complied with. Such verification of self-reporting allow for a lower audit coverage than if all discards are estimated through video audit. If noncompliance is detected, a larger percentage or even full audit of video footage from the given vessel can be conducted to support managers' claim of detected infringements. This actually happened in the CCQM in 2011 when underreporting of discards was detected for two vessels (Ulrich et al., 2015). In the last six months of the CCQM, recorded discards were stored as images in addition to the species mass and length estimates made by auditors. Such recording of discards will allow for precise documentation if fisheries managers need to take legal actions against vessels suspected of non-compliance. The fact that the video audit conducted in the CCQM detected non-compliance with the LO in 2016 emphasizes this. If the LO was fully complied with, no discards of haddock would have taken place in 2016 from the participating vessels as all of them had fisheries that were covered by the LO in the North Sea and Skagerrak and therefore had to bring all catches of haddock ashore. However, discarding of haddock was observed. This means that although fishers knew they were monitored by EM they still behaved in non-compliance with the LO. Whether this is because fishers forget they are monitored, lack knowledge about the species subject to the LO or something else is unknown. But it does highlight that EM is a tool for monitoring, and it must be supplied with enforcement actions (such as fines) to ensure that the LO will be complied with, if even fishers monitored by EM do not comply with the regulation, even though compliance with the LO was specified in the trial conditions. This is of importance not least when considering that critics of the results that can be derived from the CCQM have pointed to a selection bias in trials, because fishers with high compliance levels were more likely to participate in the trial (Msomphora and Aanesen, 2015). Despite its relevance, EM has so far only been used on a voluntary basis in the $\mathrm{EU}$, although at the time of writing, the first uses of EM are being implemented as a response to the LO (STECF, 2018). A central reason for this is likely the reluctance towards EM which has been reported among fishers and relates to the perceived intrusion and surveillance level that EM represents (FiskerForum, 2018; Mangi et al., 2015; PletHansen et al., 2017).

\subsection{Future developments}

The main future development for EM would be a larger uptake of this MCS tool in more fisheries, a trend that is indeed already ongoing as more and more fisheries around the globe either investigate or use EM as a MCS tool (van Helmond et al., in review). From a technical perspective, the next step forward for EM is likely the incorporation of automated image analysis. A scheme where computer software review recorded video sequences would allow for much faster audit than even the best trained personnel. Some of the reservations against video-based MCS measures could also be countered by such a scheme, because the surveillance would be non-human and therefore would only "see" the discards. Another option would be for automated image recognition to estimate the full catch prior to catch processing rather than estimating the discards. However, the current level of available image recognition software is to our knowledge still not sufficient to allow for species identification and automatic length measurements on the conveyor belt on-board commercial fishing vessels, although attempts have been made to achieve this (French et al., 2015) and developments within this field are rapid at the moment. The fact that automated species registration and length measurement in the actual trawl has now become available does support the possibility of having species recognition and length measurements run automatically in the future (Scantrol Deep Vision AS, 2017). If such automatization of video audit were to be incorporated, this would strengthen the quality of EM data regardless of whether the usage is for enforcement of compliance or estimation of discards. Unless all discards from all vessels are counted, the number of fish discarded will essentially still be unknown. Extrapolation of recorded discard data can be used and calibrated based on full account from EM-vessels but this will inherently carry the risk of inducing errors or bias. Automated image recognition may remove this issue by making it possible to identify virtually all discards in a fishery, leading to better data for stock assessments too. Some limitations in linking scientific survey data and EM data will remain. The identification of numbers, species and length is possible by use of EM systems as the one presented here, but the mass has to be calculated based on a length-mass relationship in order to compare the discards with quota settings. The use of the length-mass relationship will inherently ignore the variation in mass due to condition of each fish which can vary significantly (Schwalme and Chouinard, 1999). This will add uncertainty to the actual mass estimate derived from EM systems relying solely on visual discard audit. Adding dynamic scales to the EM system and incorporating discarding procedures for weighing discards would eliminate this uncertainty. However, this will likely extend the needed catch processing times due to the extra handling of unwanted catches which has been pointed to as an issue in other EM trials using either a compulsory system where discards would be binned in baskets or a system with individual arrangement of discards for clearer view (Ulrich et al., 2015; van Helmond et al., 2017). Additionally, this will not alter the fact that age determination is not possible with video footage, meaning that EM with video cannot address the difficulties related to comparing commercial mass-based catches with age-based scientific stock assessment. Linking EM with video to eLog records at a haul-by-haul basis allows for the determination of discards, discard rates and full catch account for each haul audited. From the spatial and temporal distribution of hauls, EM data can thus be used to highlight times and areas where discarding is likely to occur. Depending on the speed of video transmission and audit, such maps could potentially help fishers improve their spatial selectivity by consulting with continuously updated maps. Additionally, linkage of EM with video data to eLog data allows, at least in Denmark, for a linkage between EM with video data and grading machine data collected from sea-packing vessels (PletHansen et al., 2018). This will allow for investigations of species' landings and discard size composition at the haul level, potentially shedding further light on the drivers behind the occurrence of unwanted catches.

\section{Conclusion}

The present study demonstrates that EM is capable of high precision detection of non-compliance with a discard ban and that developments in the transmission of EM data allowed for a smoother and more reliable MCS system. EM systems can still be improved, especially if automated image analysis could be incorporated. Our results point to possible reasons behind and patterns within the discarding practice and the scope and presence of some unwanted catches. Further analysis of discard patterns, both temporal and spatial, can be performed with the collected EM data presented in this study.

\section{Contributors}

- Clara Ulrich (CU) and Kristian Plet-Hansen (KP) designed the study. - KP and Heiðrikur Bergsson (HB) did the data collection.

- Data analysis and interpretation were done by all authors (KP, HB, 
$\mathrm{CU})$.

- KP drafted the article.

- All authors made critical revision of the article (KP, HB, CU).

- Final approval of the version to be published was done by all authors (KP, HB, CU).

\section{Declarations of interest}

None.

\section{Acknowledgements}

This work has received funding from the Horizon 2020 Programme under grant agreement DiscardLess number 633680. This support is gratefully acknowledged. The CCQM project was funded by the European Maritime and Fisheries Fund and The Danish Fisheries Agency. The authors thankfully acknowledge this as well as the sharing of data. Finally, a thank to Microsoft Denmark for providing an overall data storage cost estimate. This estimate is non-binding and reservations are taken due to lack of information on specific details on EM setup and design.

\section{Appendix A. Supplementary data}

Supplementary material related to this article can be found, in the online version, at doi:https://doi.org/10.1016/j.fishres.2019.03.009.

\section{References}

Anchor Lab K/S, 2017. Black Box Video. [WWW Document]. URL http://www anchorlab.dk/EFM.aspx?tab = Video (Accessed 6 June 2018).

Andersen, P., Andersen, J.L., Frost, H., 2010. ITQs in Denmark and resource rent gains ITQs in Denmark and resource rent gains. Mar. Resour. Econ. 25, 11-22. https://doi. org/10.5950/0738-1360-25.1.11.

Baudron, A.R., Fernandes, P.G., 2015. Adverse consequences of stock recovery: European hake, a new "choke" species under a discard ban? Fish Fish. 16, 563-575. https://doi. org/10.1111/faf.12079.

Bergsson, H., Plet-Hansen, K.S., 2016. Final Report on Development and Usage of Electronic Monitoring Systems as a Measure to Monitor Compliance With the Landing Obligation - 2015. https://doi.org/10.13140/RG.2.2.13561.67683.

Bergsson, H., Plet-Hansen, K.S., Jessen, L.N., Jensen, P., Bahlke, S.Ø., 2017. Final Report on Development and Usage of REM Systems Along With Electronic Data Transfer As a Measure to Monitor Compliance With the Landing Obligation - 2016. https://doi. org/10.13140/RG.2.2.23628.00645.

Catchpole, T.L., Ribeiro-santos, A., Mangi, S.C., Gray, T.S., Hedley, C., 2017. The challenges of the landing obligation in EU fisheries. Mar. Policy 82, 76-86. https://doi org/10.1016/j.marpol.2017.05.001.

Catchpole, T.L., Elliott, S., Peach, D., Mangi, S.C., Gray, T.S., 2018. How to deal with the EU landing obligation: Lessons from an English discard ban sea trial. ICES J. Mar. Sci. 75, 270-278. https://doi.org/10.1093/icesjms/fsx119.

Dalskov, J., Kindt-Larsen, L., 2009. Final Report of Fully Documented Fishery.

Dalskov, J., Håkansson, K.B., Olesen, H.J., 2011. Final Report on the Danish Catch Quota Management Project 2010.

Dalskov, J., Olesen, H., Møller, E., Jensen, S., Jensen, M., Schultz, F., Schou, M., 2012. Danish Catch Quota Management Trials- Application and Results.

EU, 2013. REGULATION (EU) No 1380/2013 OF THE EUROPEAN PARLIAMENT AND OF THE COUNCIL Of 11 December 2013 on the Common Fisheries Policy, Amending Council Regulations (EC) No 1954/2003 and (EC) No 1224/2009 and Repealing Council Regulations (EC) No 2371/2002 and (EC, Official Journal of the European Union.

EU, 2015. COMMISSION DELEGATED REGULATION (EU) 2015/2440 of 22 October 2015 establishing a discard plan for certain demersal fisheries in the North Sea and in Union waters of ICES Division IIa. Off. J. Eur. Union L 336/42.

European Union Committee, H. of L, 2019. Fisheries: Implementation and Enforcement of the EU Landing Obligation.

FiskerForum, 2018. DTU smidt i land af vrede fiskere. [WWW Document]. FiskerForum.dk. URL http://fiskerforum.dk/erhvervsnyt/a/dtu-smidt-i-land-af vrede-fiskere-20022018 (Accessed 6 June 2018).

French, G., Fisher, M.H., Mackiewicz, M., Needle, C.L., 2015. Convolutional neural networks for counting fish in fisheries surveillance video. Workshop on Machine Vision of Animals and Their Behaviour 7.1-7.10. https://doi.org/10.5244/C.29.MVAB.7.

Gilman, E., Legorburu, G., Fedoruk, A., Heberer, C., Zimring, M., Barkai, A., 2019. Increasing the functionalities and accuracy of fisheries electronic monitoring systems. Aquat. Conserv. Mar. Freshw. Ecosyst. https://doi.org/10.1002/aqc.3086. In press. Gullestad, P., Blom, G., Bakke, G., Bogstad, B., 2015. The "Discard Ban Package": experiences in efforts to improve the exploitation patterns in Norwegian fisheries. Mar. Policy 54, 1-9. https://doi.org/10.1016/j.marpol.2014.09.025.

Hedley, C., Catchpole, T., Santos, A.R., 2015. The Landing Obligation and Its Implications on the Control of Fisheries. https://doi.org/10.2861/694624.

Hersoug, B., 2018. "After all these years" - New Zealand's quota management system at the crossroads. Mar. Policy 92, 101-110. https://doi.org/10.1016/j.marpol.2018.02. 010.

James, K.M., Campbell, N., Viðarsson, J.R., Vilas, C., Plet-Hansen, K.S., Borges, L., PérezBouzada, J., van Helmond, A.T.M., Abad, E., González, Ó., Perez Martin, R.I. Quinzán, M., Antelo, L.T., Valeiras, J., Ulrich, C., 2019. Tools and technologies for the monitoring, control and surveillance of unwanted catches. In: Uhlmann, S.S., Ulrich, C., Kennelly, S.J. (Eds.), The European Landing Obligation - Reducing Discards in Complex, Multi-Species and Multi-Jurisdictional Fisheries. Springer International Publishing AG, part of Springer Nature, Dordrecht, pp. 363-382.

Kindt-Larsen, L., Kirkegaard, E., Dalskov, J., 2011. Fully documented fishery : a tool to support a catch quota management system. ICES J. Mar. Sci. https://doi.org/10. 1093/icesjms/fsr065.

Mangi, S.C., Dolder, P.J., Catchpole, T.L., Rodmell, D., De Rozarieux, N., 2015. Approaches to fully documented fisheries : practical issues and stakeholder perceptions. Fish Fish. 426-452. https://doi.org/10.1111/faf.12065.

Mortensen, L.O., Ulrich, C., Jakob, H., Berg, C.W., Tzamouranis, N., Dalskov, J., 2017 Effectiveness of fully documented fisheries to estimate discards in a participatory research scheme. Fish. Res. 187, 150-157. https://doi.org/10.1016/j.fishres.2016. 11.010.

Msomphora, M.R., Aanesen, M., 2015. Is the catch quota management (CQM) mechanism attractive to fishers? A preliminary analysis of the Danish 2011 CQM trial project. Mar. Policy 58, 78-87. https://doi.org/10.1016/j.marpol.2015.04.011.

Needle, C.L., Dinsdale, R., Buch, T.B., Catarino, R.M.D., Drewery, J., Butler, N., 2015. Scottish science applications of remote electronic monitoring. ICES J. Mar. Sci. 72, 1214-1229. https://doi.org/10.1093/icesjms/fsu225.

Plet-Hansen, K.S., Bergsson, H., Mortensen, L.O., Ulrich, C., Dalskov, J., Jensen, S.P., Olesen, H.J., 2015. Final Report on Catch Quota Management and Choke Species 2014. https://doi.org/10.13140/RG.2.2.11883.95524.

Plet-Hansen, K.S., Eliasen, S.Q., Mortensen, L.O., Bergsson, H., Olesen, H.J., Ulrich, C., 2017. Remote electronic monitoring and the landing obligation - some insights into fishers' and fishery inspectors' opinions. Mar. Policy 76, 98-106. https://doi.org/10. 1016/j.marpol.2016.11.028.

Plet-Hansen, K.S., Larsen, E., Mortensen, L.O., Nielsen, J.R., Ulrich, C., 2018. Unravelling the scientific potential of high resolution fishery data. Aquat. Living Resour. 31https://doi.org/10.1051/alr/2018016. 14 pp.

Reddy, P., 2017. Fisheries (Electronic Monitoring on Vessels) Regulations 2017. Parliamentary Counsel Office, New Zealand.

Scantrol Deep Vision AS, 2017. Deep Vision. [WWW Document]. URL https://www. deepvision.no/deep-vision/deep-vision (Accessed 6 June 2018). .

Schwalme, K., Chouinard, G.A., 1999. Seasonal dynamics in feeding, organ weights, and reproductive maturation of Atlantic cod (Gadus morhua) in the southern Gulf of St Lawrence. ICES J. Mar. Sci. 56, 303-319. https://doi.org/10.1006/jmsc.1999.0458.

Stanley, R.D., McElderry, H., Mawani, T., Koolman, J., 2011. The advantages of an audit over a census approach to the review of video imagery in fishery monitoring. ICES J. Mar. Sci. 68, 1621-1627. https://doi.org/10.1093/icesjms/fsr058.

STECF, 2017. Scientific, Technical and Economic Committee for Fisheries (STECF) - The 2017 Annual Economic Report on the EU Fishing Fleet (STECF-17-12). https://doi. org $/ 10.2760 / 36154$

STECF, 2018. Scientific, technical and economic committee for fisheries (STECF). 59th Plenary Meeting Report (PLEN-18-03). https://doi.org/10.2760/335280.

Ulrich, C., Dalskov, J., Egekvist, J., Håkansson, K.B., Olesen, H.J., 2013. Behind the Shine: An Appraisal of Five Years of Danish CCTV Trials. 2012-2013.

Ulrich, C., Olesen, H.J., Bergsson, H., Egekvist, J., Håkansson, K.B., Dalskov, J., Kindtlarsen, L., Storr-paulsen, M., 2015. Discarding of cod in the Danish fully documented fisheries trials. ICES J. Mar. Sci. 72, 1848-1860. https://doi.org/10.1093/icesjms/ fsv028.

van Helmond, A.T.M., Chen, C., Trapman, B.K., Kraan, M., Poos, J.J., 2016. Changes in fishing behaviour of two fleets under fully documented catch quota management: same rules, different outcomes. Mar. Policy 67, 118-129. https://doi.org/10.1016/j. marpol.2016.01.029.

van Helmond, A.T.M., Chen, C., Poos, J.J., 2017. Using electronic monitoring to record catches of sole (Solea solea) in a bottom trawl fishery. ICES J. Mar. Sci. J. du Cons. 74https://doi.org/10.1093/icesjms/fsw241. fsw241.

van Helmond, A., Mortensen, L.O., Plet-Hansen, K.S., Ulrich, C., Needle, C.L., Oesterwind, D., Kindt-Larsen, L., Catchpole, T., Mangi, S., Zimmermann, C., Olesen, H.J., Bailey, N., Bergsson, H., Dalskov, J., Elson, J., Hosken, M., Poos, J.J., European experiences on the use of Remote Electronic Monitoring. Fish Fish. In review. 